\title{
Low temperature spark plasma sintering of YIG powders
}

\author{
Authors: L. Fernandez-Garcia ${ }^{\text {a }}$, M. Suarez ${ }^{\text {a,b* }}$, J. L. Menendez ${ }^{\text {a }}$ \\ Affiliations: a Department of Nanostructured Materials, Centro de Investigación en Nanomateriales y \\ Nanotecnología (CINN). Principado de Asturias - Consejo superior de Investigaciones Científicas (CSIC) \\ - Universidad de Oviedo (UO). Parque Tecnológico de Asturias, 33428 Llanera, (Asturias), Spain. \\ ${ }^{\mathrm{b}}$ Fundación ITMA, Parque Tecnológico de Asturias, 33428, Llanera, Spain
}

\begin{abstract}
A transition from a low to a high spin state in the magnetization saturation between 1000 and $1100{ }^{\circ} \mathrm{C}$ calcination temperature is observed in YIG powders prepared by oxides mixture. Spark plasma sintering of these powders between 900 and $950{ }^{\circ} \mathrm{C}$ leads to dense samples with minimal formation of $\mathrm{YFeO}_{3}$, opening the way to cosintering of YIG with metals or metallic alloys. The optical properties depend on the sintering stage: low (high) density samples show poor (bulk) optical absorption.
\end{abstract}

Keywords: Ceramic; Magnetically ordered materials; Sintering; Magnetisation; Optical spectroscopy; Magnetic measurements.

\footnotetext{
* Corresponding autor. Tel.: +34 9859800 58; fax: +34 985265574

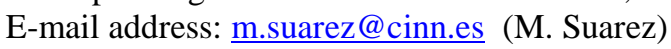




\section{Introduction}

Ferromagnetic yttrium iron garnet $\mathrm{Y}_{3} \mathrm{Fe}_{5} \mathrm{O}_{12}$ is an interesting material since it shows a large Faraday rotation at the onset of a strong optical absorption in the visible range near $2.5 \mathrm{eV}$ [1]. Also, in the microwave regime, it has the highest quality factor among the magnetic oxides, that is, it shows the smallest linewidth $(\Delta \mathrm{H})$ in magnetic resonance [2] as well as low dielectric loss tangent [3], which renders it useful for several applications in this spectral range such as circulators, oscillators and phase shifters [4]. One of the most significant advantages of this garnet system is that it allows tailoring different properties by combining it or doping it with other elements or materials. This way, solid solutions with $\mathrm{Gd}_{3} \mathrm{Fe}_{5} \mathrm{O}_{12}$ or $\mathrm{Y}_{3} \mathrm{Al}_{5} \mathrm{O}_{12}$ allow tailoring the saturation magnetization of the system. Also, other works report enhancements in the magnetooptical Kerr effect in Au/Bi:YIG granular films [5] and Au particles embedded in Bi:YIG [6] or in the Faraday effect [7].

On the other hand, the development of devices based on the materials reported above rely on an adequate sintering, particularly on sintering of YIG at low enough temperatures to avoid melting of the metal in the composites mentioned above or the electrodes, such as Ag-Pd alloy, in multilayer ceramic devices [8], that is, below 1000 ${ }^{\circ} \mathrm{C}$, while keeping the optical and magneto-optical properties of bulk YIG. For this reason, many efforts have been devoted to sintering. Initially, sintering of YIG required high sintering temperatures $\left(>1400^{\circ} \mathrm{C}\right)$ and long holding times $(>10 \mathrm{~h})$ in conventional furnaces. In some cases, the use of additives was shown to reduce the sintering temperature [9-11], whereas in other works, non conventional sintering techniques, mainly microwave sintering, were used $[12,13]$ in order to reduce the sintering temperature below $1000{ }^{\circ} \mathrm{C}$. 
In this paper we report about low temperature spark plasma sintering of YIG powders and how the optical activity is modified during sintering in the range $2-6.5 \mathrm{eV}$; how the optical transitions and, therefore, the optical properties are modified as a function of the sintering stage.

\section{Experimental procedures}

YIG ferrite powders having stoichiometric compositions of $\mathrm{Y}_{3} \mathrm{Fe}_{5} \mathrm{O}_{12}$ were prepared by the solid state reaction method. The raw materials, $\mathrm{Fe}_{2} \mathrm{O}_{3}$ (Aldrich, 99.9\% purity) with the particle size of around $5.0 \mu \mathrm{m}$ and $\mathrm{Y}_{2} \mathrm{O}_{3}$ (Cerac, $99.99 \%$ purity) with the particle size of around $9.0 \mu \mathrm{m}$, were mixed in propanol and ball milled for $1 \mathrm{~h}$. The powders were thermally calcined in air between 800 and $1200{ }^{\circ} \mathrm{C}$ for $2 \mathrm{~h}$ to obtain pure yttrium iron garnet. The grain size of the final powders was measured by granulometric analysis (FRITSCH Analysette 22 MicroTec XT) being around $10 \mu \mathrm{m}$.

These powders were uniaxially pressed at $30 \mathrm{MPa}$ and sintered at a heating rate of $50{ }^{\circ} \mathrm{C}$ $\min ^{-1}$ in a spark plasma sintering apparatus (FCT-HP D25/1) under an applied pressure of $80 \mathrm{MPa}$ and in vacuum $\left(10^{-1} \mathrm{mbar}\right)$. The final sintering temperatures were varied from 900 to $950{ }^{\circ} \mathrm{C}$ and holding times from 1 to $30 \mathrm{~min}$.

The density of the specimens was measured by powder picnometry (model GeoPyc 1360, MICROMERITICS ${ }^{\circledR}$ ) using a theoretical density of $5.172 \mathrm{~g} \cdot \mathrm{cm}^{-3}$ [14].

Powder X-ray diffraction analysis (D8 Advance, BRUKER) was used to determine the crystalline phases of the milled powder. The average size grain of the sintered samples was characterized by scanning electron microscopy (SEM, DSM950 Zeiss). The hysteresis loops were measured with an alternative gradient magnetometer (AGM, MicroMag ${ }^{\mathrm{TM}}$, Princeton Measurements Corporation). Ellipsometry (SOPRA GES E5) was used to measure the dielectric constant of the sintered samples. 


\section{Results and discussion}

The mixed powders were calcined at different temperatures, ranging from 800 to $1200{ }^{\circ} \mathrm{C}$ and the phase transformations studied by XRD (Fig. 1). Calcination temperatures of 800 and $900{ }^{\circ} \mathrm{C}$ do not allow a transformation of the $\mathrm{Fe}_{2} \mathrm{O}_{3}$ and $\mathrm{Y}_{2} \mathrm{O}_{3}$ precursors into the YIG phase. At $1000^{\circ} \mathrm{C}$, the transformation starts with diffraction maxima corresponding to YIG being clearly defined, but still the peaks corresponding to the $\mathrm{Fe}_{2} \mathrm{O}_{3}$ and $\mathrm{Y}_{2} \mathrm{O}_{3}$ are present. 1100 and $1200{ }^{\circ} \mathrm{C}$ are high enough temperatures to allow a full transformation into YIG $[15,16]$ with no other phases being present, in particular no $\mathrm{YFeO}_{3}$ was detected. The average particle determined after calcination at $1100^{\circ} \mathrm{C}$ was $6 \mu \mathrm{m}$.

The saturation magnetization of the powders (see inset in Fig. 1) also follows the trend indicated by the structural characterization. There is a clear transition between $1000{ }^{\circ} \mathrm{C}$ and $1100{ }^{\circ} \mathrm{C}$ from a low spin state to a high spin state, as the saturation magnetization increases from almost zero at $1000^{\circ} \mathrm{C}$ to $27 \mathrm{emu} / \mathrm{cc}$, the YIG bulk value, at $1100{ }^{\circ} \mathrm{C}$ calcination temperature. This result agrees well with other routes already reported in the literature $[17,18]$.

Powders calcined at $1200^{\circ} \mathrm{C}$ were further spark plasma sintered at temperatures between 900 and $950{ }^{\circ} \mathrm{C}$ with holding times varied between 1 and 30 minutes. In all cases, YIG was the main phase and only in the case of long holding times, minor peaks corresponding to the ortoferrite $\mathrm{YFeO}_{3}$ were present (Fig. 2). From Van Hook's works on the $\mathrm{Y}_{2} \mathrm{O}_{3}-\mathrm{Fe}_{2} \mathrm{O}_{3}$ phase diagram $[19,20]$, no segregation of the $\mathrm{YFeO}_{3}$ ortoferrite should take place below $1500{ }^{\circ} \mathrm{C}$. Although, it was then shown that this transition temperature decreases when the oxygen partial pressure is reduced; sintering in vacuum 
should not be expected at such low temperature $\left(900-950{ }^{\circ} \mathrm{C}\right)$. However, spark plasma sintering is a largely out of equilibrium sintering process and this point, together with the applied pressure, may be the reason at the origin of the presence of the ortoferrite phase. Therefore, although sintering at higher temperature allows increasing the density of the sintered materials, an excess in the sintering temperature may lead to the presence of $\mathrm{YFeO}_{3}$. Therefore, in this system it is critical to tune both the sintering temperature and the holding time in order to have pure and dense YIG materials. It is important to compare this result with previous ones obtained on conventionally sintered YIG in which the temperatures required to obtain a sintered piece reached $1300^{\circ} \mathrm{C}[18,21]$ and were in any case, over $1000^{\circ} \mathrm{C}$ [22]. Just Q. Yang et al. [13] using another non conventional sintering technique, microwave sintering, has reported sintering temperatures below $1000{ }^{\circ} \mathrm{C}$.

In all cases, the magnetic characterization shows that the saturation magnetization is close to the bulk value in the sintered materials, with the samples sintered at the highest temperatures and the longest holding times showing a slight decrease of the saturation magnetization, not larger than $10 \%$ in any case, probably due to the presence of both the $\mathrm{YFeO}_{3}$ phase and $\mathrm{Fe}_{2} \mathrm{O}_{3}$. As expected, all the sintered samples turned to behave as soft magnets, with coercive fields in the 7-12 Oe range in all cases.

Further insight about the garnet structure can be gained by ellipsometry. Fig. 3 shows the imaginary part, which accounts for the absorption, of the diagonal component of the dielectric tensor for the two extreme samples, that is, sintered at $900{ }^{\circ} \mathrm{C}$ for 1 minute and sintered at $950{ }^{\circ} \mathrm{C}$ for 15 minutes. The values of both the real and the imaginary part of the diagonal component of the dielectric tensor increase in all the samples studied with 
the sintering temperature and the holding times. Although the garnet structure is the only one present according to XRD, the structure at an atomic level may be distorted in the non dense materials. Scanning electron microscope images (Fig. 4) show rounded grains, corresponding to an early stage of sintering in which atomic diffusion is taking place, in the case of the sample sintered at $900{ }^{\circ} \mathrm{C}$ for 1 minute, whereas facets corresponding to a structure with a higher crystallinity are observed in the sample sintered at $950{ }^{\circ} \mathrm{C}$ for 15 minutes. G. A. Allen and G. F. Dionne have presented a paper [23], with detailed information about the ellipsometry (transitions) of YIG in the 2-4 eV range. The fitting procedure considered here the transitions identified in that work and shown in Table I, plus two additional ones, located at 5.49 and $6.68 \mathrm{eV}$, in order to fit the high energy region of the spectrum, on the other hand, the region with the highest values of the dielectric constant. The $\varepsilon_{0}$ " spectra were fitted with Gaussian lines of full width at half maximum $\Gamma_{0}$. Although minor differences can be found in the intensity of the high energy transitions $\varepsilon_{0} "\left(\omega_{0}\right)$, over $4 \mathrm{eV}$, between both samples; the most remarkable differences are found in the low energy transitions, which have been identified with crystal field transitions [24]. The intensity of the low energy transitions is very low or almost negligible in the $900{ }^{\circ} \mathrm{C}$ sintering temperature and it increases by one order of magnitude in the sample sintered at $950{ }^{\circ} \mathrm{C}$ for 15 minutes. This result reinforces the hypothesis that the crystal structure is being distorted during sintering.

\section{Conclusions}

It has been shown that it is possible to obtain dense materials by spark plasma sintering at temperatures well below $1000{ }^{\circ} \mathrm{C}$, which opens the route to cosintering of YIG with noble metals such as $\mathrm{Ag}$ or Pd. Also, although increasing the sintering temperature allows increasing the density of the sintered materials, an excess in the 
sintering temperature or in the holding time may lead to a decomposition of the YIG into $\mathrm{YFeO}_{3}$ and $\mathrm{Y}_{2} \mathrm{O}_{3}$ which must be taken into account when it is imperative to obtain just the garnet phase. Finally, it has been shown that the electronic structure is particularly sensitive to the sintering stage. In particular, the intensity of the transitions related to the crystal field decreases and almost disappears in the poorly sintered samples. 


\section{Acknowledgements}

The authors want to acknowledge the Spanish Ministry of Education and Science and UE for funding through project MAT2009-14534-C03-03. One of us, L. Fernandez-Garcia, wants to acknowledge JAE program for $\mathrm{PhD}$ grant. 
Figures

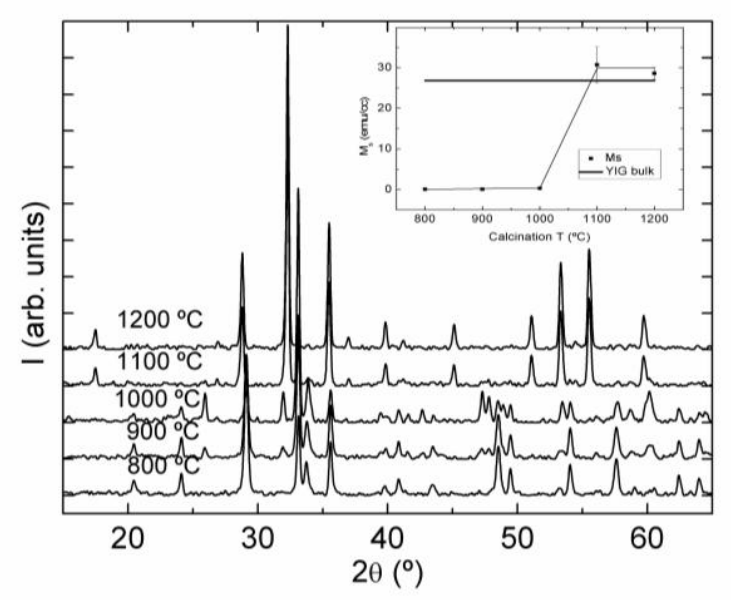

Fig. 1. 


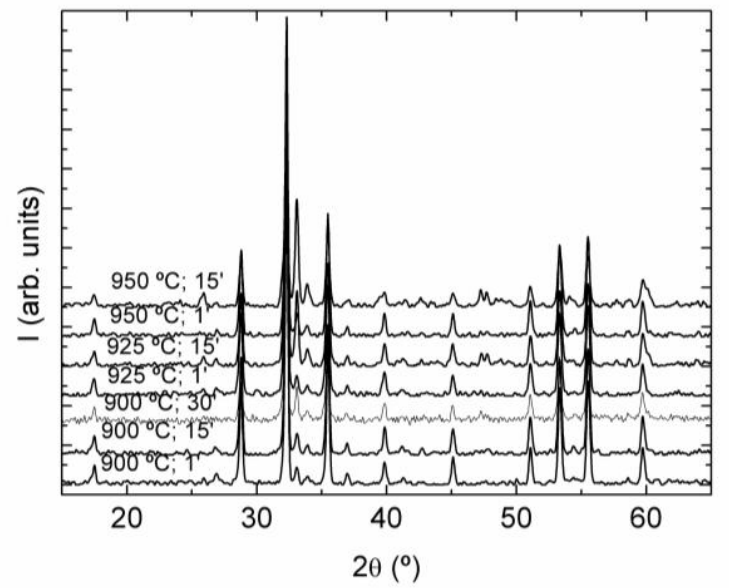

Fig. 2. 


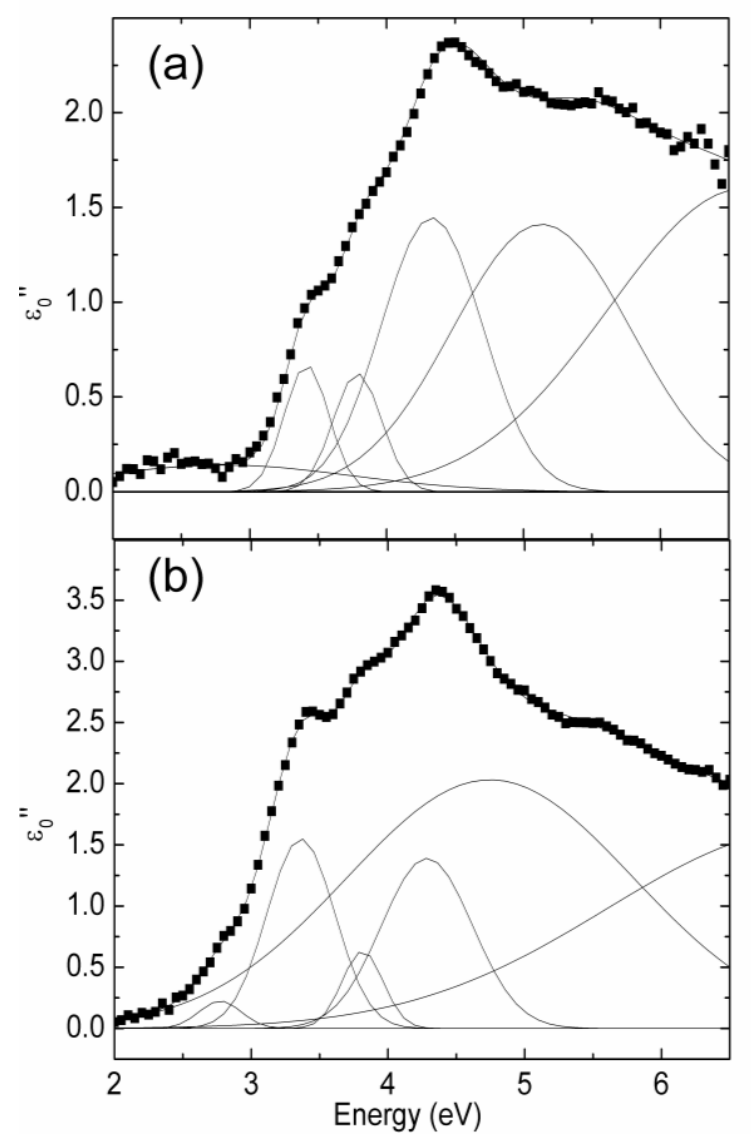

Fig. 3. 


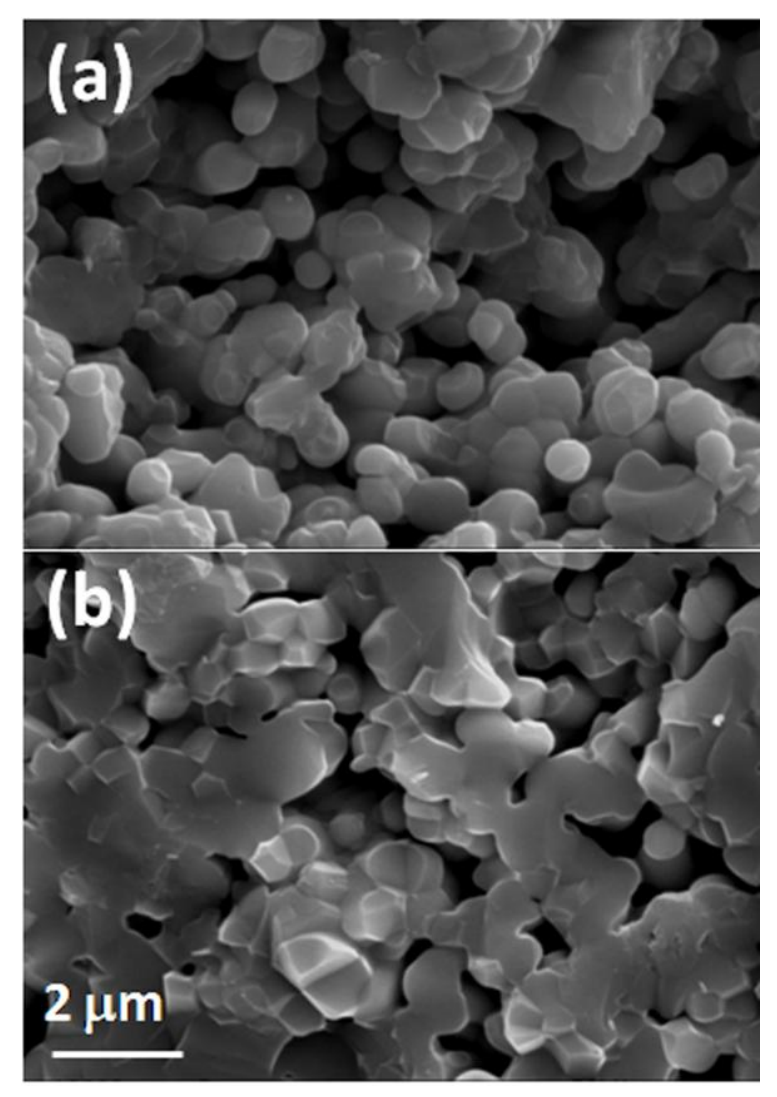

Fig. 4. 


\section{Captions}

Fig.1. X-ray diffractogram of the oxides mixture calcined to temperatures between 800 and $1200^{\circ} \mathrm{C}$. Inset shows the evolution of the saturation magnetization as a function of the calcination temperature.

Fig. 2. XRD diffractograms for the SPSed samples.

Fig. 3. Imaginary part of the diagonal element of the dielectric tensor for the samples sintered at (a) $900{ }^{\circ} \mathrm{C}$ for 1 minute and (b) $950{ }^{\circ} \mathrm{C}$ for 15 minutes.

Fig. 4. SEM images corresponding to samples SPSed at (a) $900{ }^{\circ} \mathrm{C}$ for 1 minute and (b) $950^{\circ} \mathrm{C}$ for 15 minutes. 
Tables

\begin{tabular}{cc}
\hline Sample & density $\left(\mathrm{g} / \mathrm{cm}^{3}\right)$ \\
\hline $900^{\circ} \mathrm{C} 1$ & $84 \%$ \\
$900^{\circ} \mathrm{C} 10^{\prime}$, & $90 \%$ \\
$900^{\circ} \mathrm{C} 30^{\prime}$ & $92 \%$ \\
$925^{\circ} \mathrm{C} 1$ & $86 \%$ \\
$925^{\circ} \mathrm{C} 15^{\prime}$ & $92 \%$ \\
$950^{\circ} \mathrm{C} 1$ & $84 \%$ \\
$950^{\circ} \mathrm{C} 15^{\prime}$ & $95 \%$ \\
\hline
\end{tabular}

Table 1. Densitites of the different sintered materials.

\begin{tabular}{ccccc}
\hline$\omega_{0}(\mathrm{eV})$ & $\varepsilon_{0}{ }^{\prime \prime}\left(\omega_{0}\right) \cdot 10^{-2}$ & $\Gamma_{0}(\mathrm{eV}) \cdot 10^{-2}$ & $\varepsilon_{0}{ }^{\prime \prime}\left(\omega_{0}\right) \cdot 10^{-2}$ & $\Gamma_{0}(\mathrm{eV}) \cdot 10^{-2}$ \\
& $900{ }^{\circ} \mathrm{C} 1 \mathrm{~min}$ & $900{ }^{\circ} \mathrm{C} 1 \mathrm{~min}$ & $950{ }^{\circ} \mathrm{C} 15 \mathrm{~min}$ & $950{ }^{\circ} \mathrm{C} 15 \mathrm{~min}$ \\
\hline 2.58 & 14.6 & 31.9 & 36.7 & 27 \\
2.75 & 0.9 & 30 & 23.8 & 10 \\
2.88 & 3.9 & 20 & 50.6 & 20 \\
3.18 & 26.8 & 31 & 164.6 & 31.3 \\
3.42 & 48.3 & 22 & 110.9 & 22.3 \\
3.7 & 45.1 & 40 & 140.8 & 39.9 \\
4.27 & 183.6 & 96.4 & 264 & 85 \\
5.49 & 198 & 142 & 247 & 161.3 \\
6.68 & 93.2 & 72.8 & 97.3 & 72.8 \\
\hline
\end{tabular}

Table 2. Parameters resulting from the permittivity fit. 


\section{References}

[1] J.F. Dillon, J. Phys. Radium. 20 (1959) 374-377.

[2] D. Warin, J.C. Mage, W. Simonet, IEEE Trans. Magn. 20 (1984) 1216-1218.

[3] C.Y. Tsay, C.Y. Liu, K.S. Liu, I.N. Lin, L.J. Hu, T.S. Yeh, J. Magn. Magn. Mater. 239 (2002) 490494.

[4] A.S. Hudson, J. Phys. D: Applied Physics. 3 (1970) 251-268.

[5] S. Tomita, T. Kato, S. Tsunashima, S. Iwata, M. Fujii, S. Hayashi, Phys. Rev. Lett. 96 (2006) 167402167405 .

[6] R. Fujikawa, A.V. Baryshev, J. Kim, H. Uchida, M. Inoue, J. Appl. Phys. 103 (2008) 07D301.

[7] H. Uchida, Y. Masuda, R.Fujikawa, A.V. Baryshev, M. Inoue, J. Magn. Magn. Mater. 321 (2009) $843-845$.

[8] C.Y. Tsay, C.Y. Liu, K.S. Liu, I.N. Lin, L.J. Hu, T.S. Yeh, Mater. Chem. Phys. 79 (2003) 138-142.

[9] Y.Y. Song, S.C. Yu, W.T. Kim, J.R. Park, T.H. Kim, J. Magn. Magn. Mater. 177-181 (1998) 257258.

[10] Tsay, C. Y., Liu, C. Y., Liu, K. S., Lin, I. N., Hu, L. J. and Yeh, T. S., J. Magn. Magn. Mater. 239 (2002) 490-494.

[11] T.J.A. Popma, A.M. Van Diepen, P.E. Bongers, J. Phys. Chem. Solids. 35 (1974) 201-205.

[12] C.-Y. Tsay, K.-S. Liu, I.-N. Lin. J. Eur. Ceram. Soc. 24 (2004) 1057-1061.

[13] Q. Yang, H. Zhang, Y. Liu, Q. Wen, L. Jia, Mater. Lett. 62 (2008) 2647-2650.

[14] International Centre for Diffraction Data, Joint Committee on Powder Diffraction Standard (JCPDS), PDF Card No. 83-1027, 86-0368, 1999.

[15] A. Sztaniszlav, E. Sterk, L. Fetter, M. Farkas-Jahnke and J. Labar, J. Magn. Magn. Mater., 41 (1984) $75-78$.

[16] P. Grosseau, A. Bachiorrini, B. Guilhot, Powder Technol. 93 (1997) 247-251.

[17] P. Vaqueiro, M.A. Lopez-Quintela, J. Rivas, J.M. Greneche, J. Magn. Magn. Mater. 169 (1997) 5658.

[18] M. Ristic, I. Nowik, S. Popovic, I. Felner, S. Music, Mater. Lett. 57 (2003) 2584-2590.

[19] H.J. Van Hook, J. Am. Ceram. Soc. 44 (1961) 208-214.

[20] H.J. Van Hook, J. Am. Ceram. Soc. 45 (1962) 162-165. 
[21] C. Torres, A.G. Arias, P. Hernandez-Gomez, C.-O. Kim, K. Hisatake, D.J. Kim, IEEE Trans. Magn. $10(2005) 3475$.

[22] H. Zhao, J. Zhou, Y. Bai, Z. Gui, L. Li, J. Magn. Magn. Mater. 280 (2004) 208-213.

[23] G.A. Allen, G.F. Dionne, J. Appl. Phys. 93 (2003) 6951-6953.

[24] G.B. Scott, D.E. Lacklison, J.L. Page, Phys. Rev. B 10 (1974) 971-986. 
Table(s)
Click here to download high resolution image

\begin{tabular}{cc}
\hline Sample & density $\left(\mathrm{g} / \mathrm{cm}^{3}\right)$ \\
\hline $900^{\circ} \mathrm{C} 1^{\prime}$ & $84 \%$ \\
$900^{\circ} \mathrm{C} 10^{\prime}$ & $90 \%$ \\
$900^{\circ} \mathrm{C} 30^{\circ}$ & $92 \%$ \\
$925^{\circ} \mathrm{C} 1^{\prime}$ & $86 \%$ \\
$925^{\circ} \mathrm{C} 15^{\prime}$ & $92 \%$ \\
$950^{\circ} \mathrm{C} 1^{\prime}$ & $84 \%$ \\
$950^{\circ} \mathrm{C} 15^{\prime}$ & $95 \%$ \\
\hline
\end{tabular}

Table 1. Denatites of the different sintered $m$ aterials. 


\begin{tabular}{ccccc}
\hline$\Phi_{0}(\mathrm{eV})$ & $\begin{array}{c}\varepsilon_{0} "\left(\Phi_{0}\right) \cdot 10^{-2} \\
900^{\circ} \mathrm{C} 1 \mathrm{~min}\end{array}$ & $\begin{array}{c}\Gamma_{0}(\mathrm{eV}) \cdot 10^{-2} \\
900^{\circ} \mathrm{C} 1 \mathrm{~min}\end{array}$ & $\begin{array}{c}\varepsilon_{0}{ }^{\prime \prime}\left(\Phi_{0}\right) \cdot 10^{-2} \\
950^{\circ} \mathrm{C} 15 \mathrm{~min}\end{array}$ & $\begin{array}{c}\Gamma_{0}(\mathrm{eV}) \cdot 10^{-2} \\
950^{\circ} \mathrm{C} 15 \mathrm{~min}\end{array}$ \\
\hline 2.58 & 14.6 & 31.9 & 36.7 & 27 \\
2.75 & 0.9 & 30 & 23.8 & 10 \\
2.88 & 3.9 & 20 & 50.6 & 20 \\
3.18 & 26.8 & 31 & 164.6 & 31.3 \\
3.42 & 48.3 & 22 & 110.9 & 22.3 \\
3.7 & 45.1 & 40 & 140.8 & 39.9 \\
4.27 & 183.6 & 96.4 & 264 & 85 \\
5.49 & 198 & 142 & 247 & 161.3 \\
6.68 & 93.2 & 72.8 & 97.3 & 72.8 \\
\hline
\end{tabular}

Table 2. Param eterstegulting from the perm ittivity fit. 
Figure(s)
Click here to download high resolution image

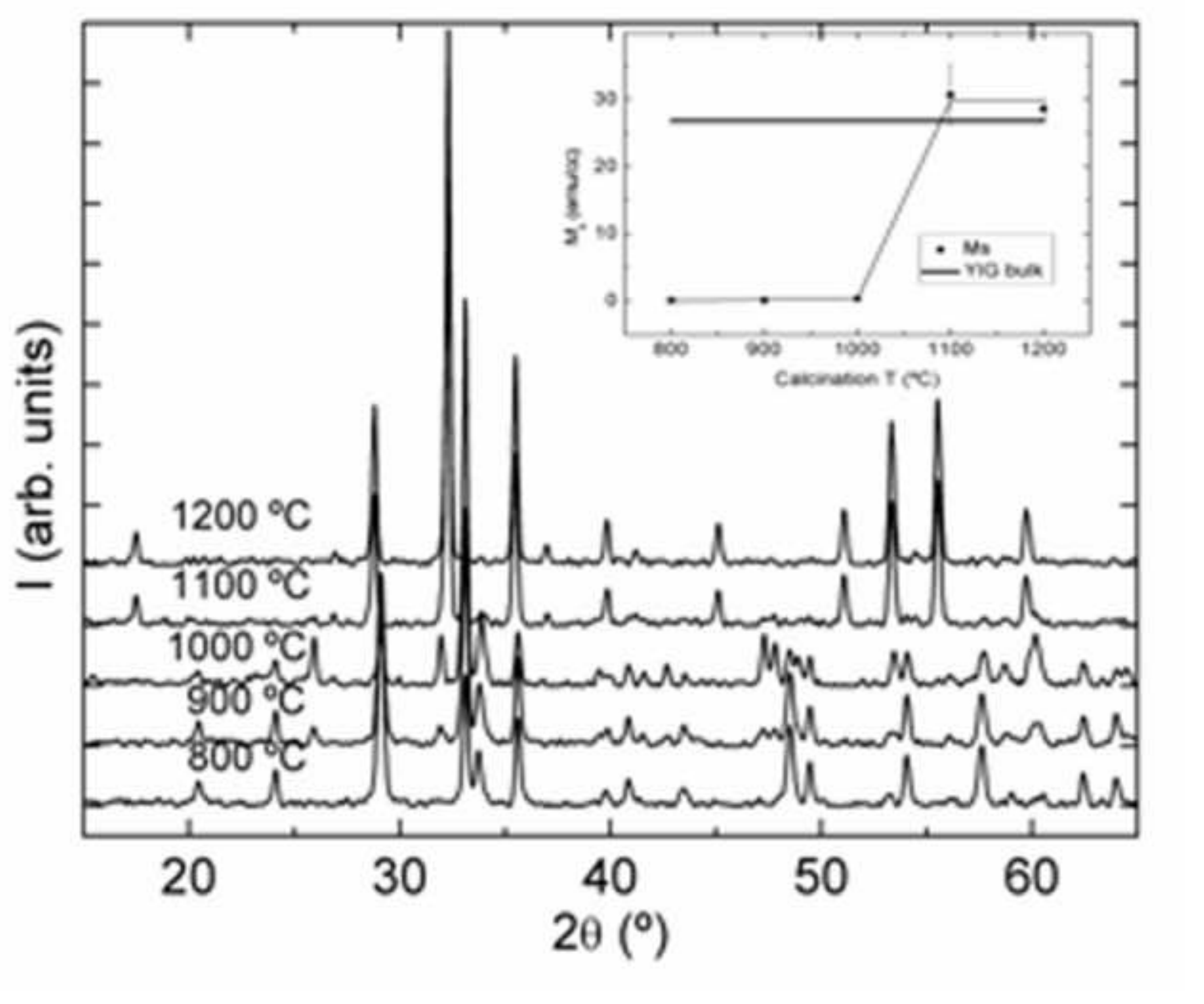


Click here to download high resolution image

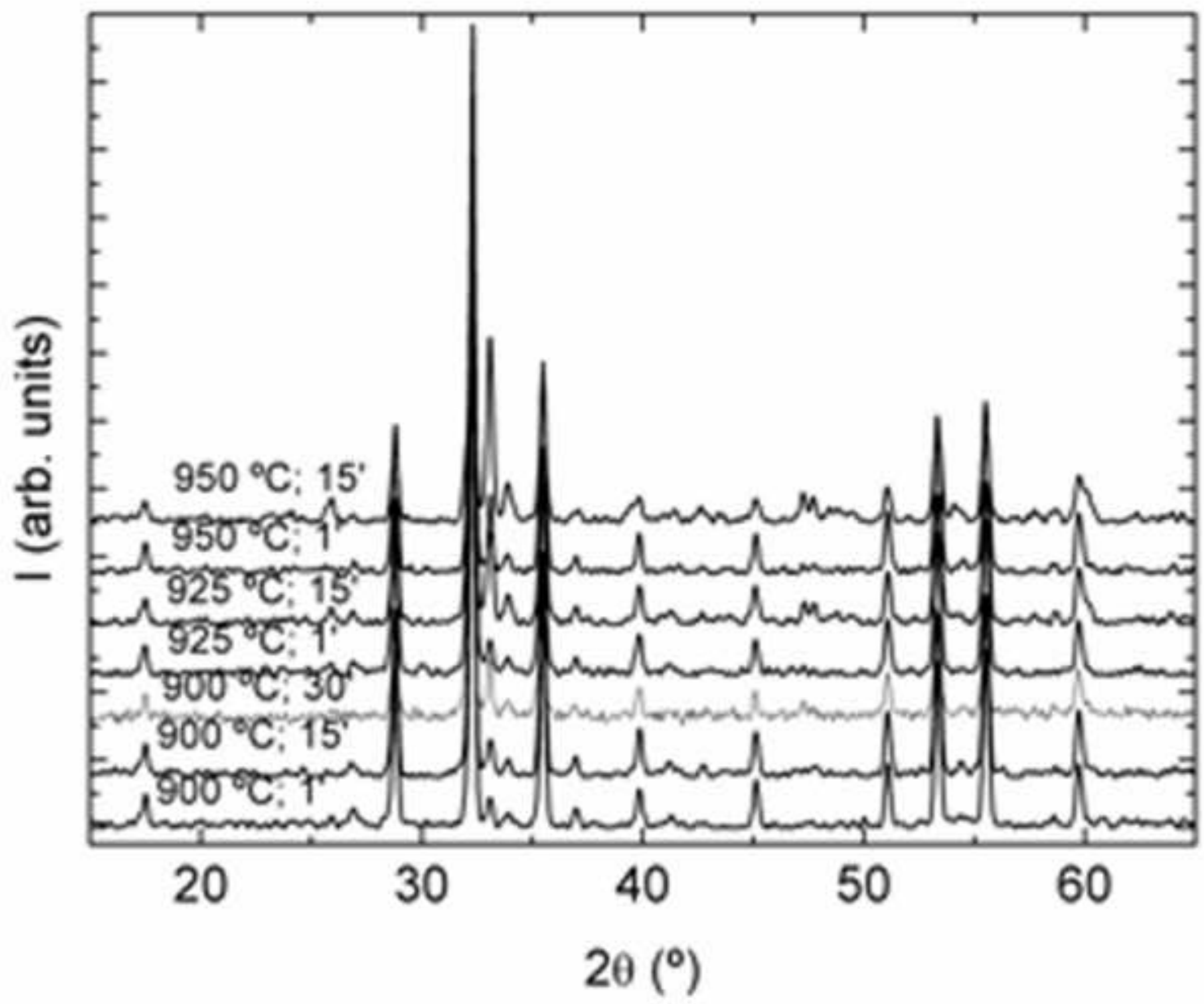


Figure(s)

Click here to download high resolution image

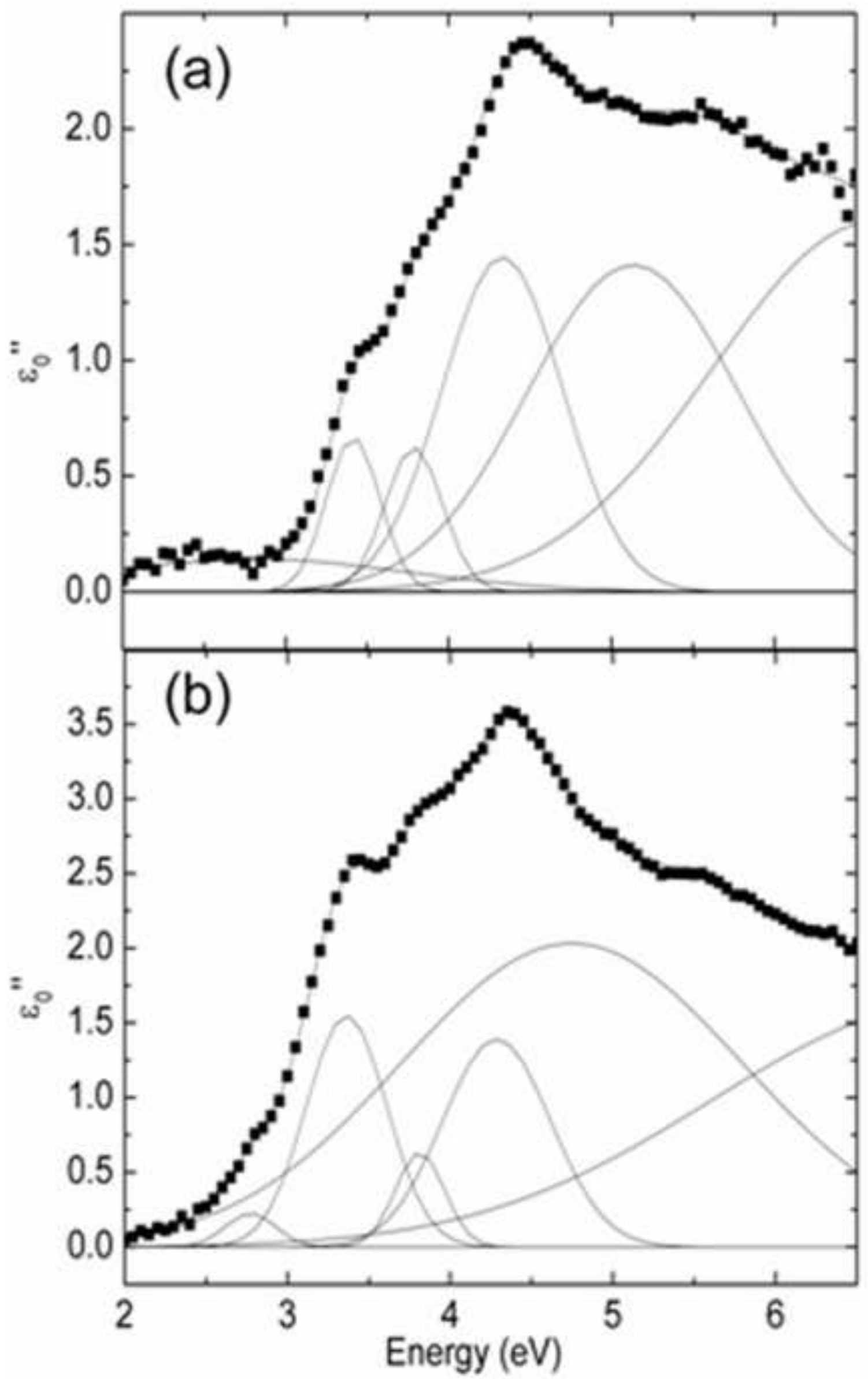




\section{Figure(s) \\ Click here to download high resolution image}
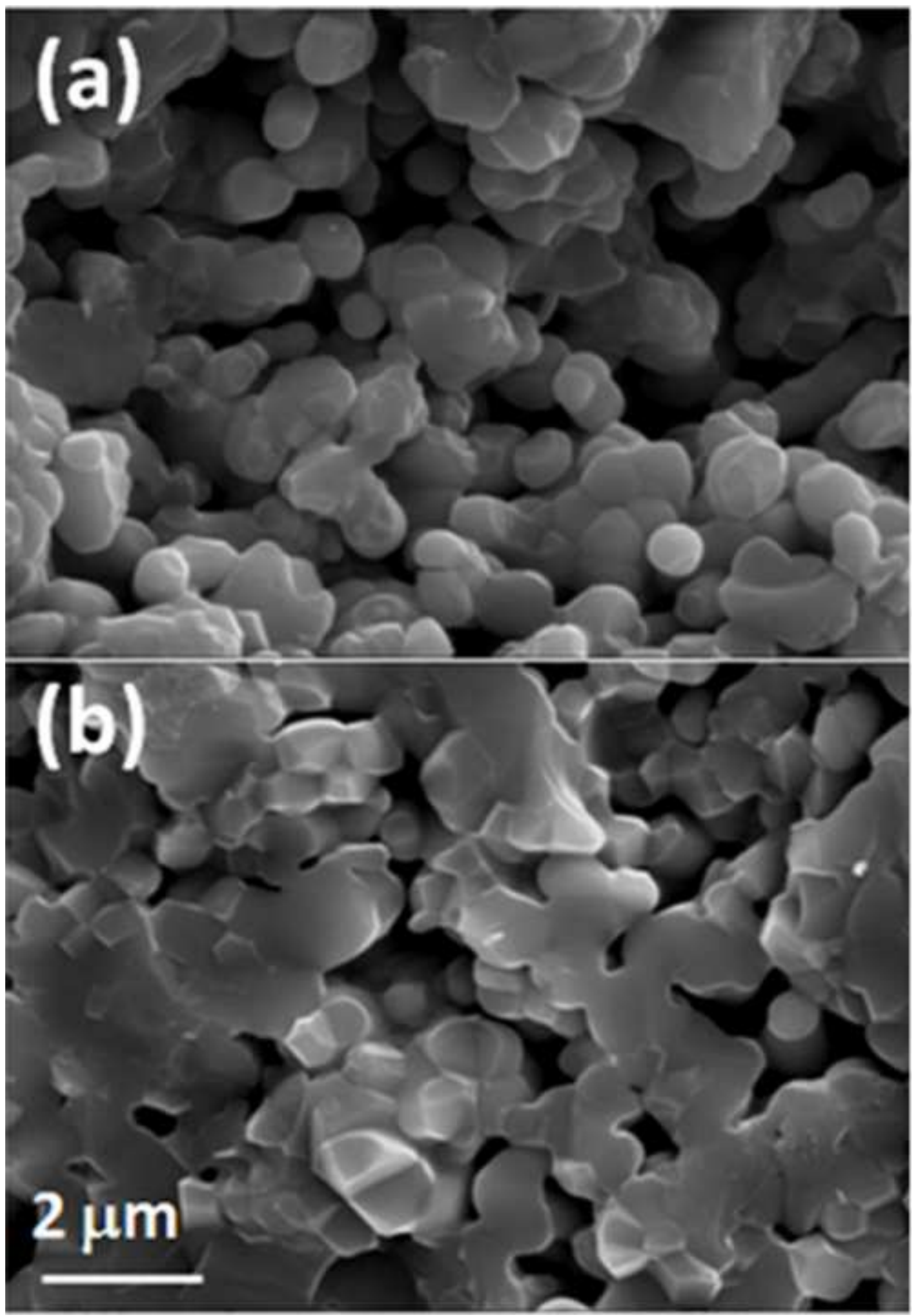